\title{
Optimization Ultrasound Assisted Extraction of Carotenoids from Rhodopseudomonas faecalis PSB-B
}

\author{
Qingping $\mathrm{Hu}^{1,2^{*}}$, Yan Wang2 \\ ${ }^{1}$ Modern College of Humanities and Sciences of Shanxi Normal University, Linfen, China \\ ${ }^{2}$ College of Life Science, Shanxi Normal University, Linfen, China \\ Email: ^hqp72@163.com
}

How to cite this paper: Hu, Q.P. and Wang, Y. (2018) Optimization Ultrasound Assisted Extraction of Carotenoids from Rhodopseudomonas faecalis PSB-B. Open Access Library Journal, 5: e5045. https://doi.org/10.4236/oalib.1105045

Received: November 12, 2018

Accepted: December 25, 2018

Published: December 28, 2018

Copyright ( $\odot 2018$ by authors and Open Access Library Inc.

This work is licensed under the Creative Commons Attribution International License (CC BY 4.0).

http://creativecommons.org/licenses/by/4.0/

\section{(c) (i) Open Access}

\begin{abstract}
The content and species of carotenoids are significantly affected by different carotenoids extraction methods. The comparison of the three methods ultrasonic assisting, grinding and $\mathrm{HCl}$ assisting on carotenoids extraction yield from Rhodopseudomonas faecalis PSB-B was carried out. Data ANOVA showed that ultrasound can greatly replace the conventional extraction. And then, based on ultrasonic assisting extraction method, the effect of ultrasonic time, solvent-solid ratio and ultrasonic power on the yield of carotenoids extracted from Rhodopseudomonas faecalis PSB-B was investigated using single factor and Box-Behnken experimental design. Under the extraction of temperature $20^{\circ} \mathrm{C}, \mathrm{N}$-hexane:Methanol (5:1), the optimal conditions for Ultrasonic assisted extraction of carotenoids found to be: Ultrasonic time $4.5 \mathrm{~min}$, Solvent-solid ratio $(\mathrm{mg} / \mathrm{ml})(10: 10)$, extraction power of $187 \mathrm{~W}$. The yield of carotenoids could reach to $16.11 \mathrm{mg} / \mathrm{L}$.
\end{abstract}

\section{Subject Areas}

Biochemistry, Bioengineering

\section{Keywords}

Rhodopseudomonas faecalis PSB-B, Carotenoids Extraction, Ultrasound Assisting

\section{Introduction}

Carotenoids are colorful compounds possessing yellow, orange and red pigments. They show important biologic activities associated with antioxidant properties, such as strengthening the immune system, decreasing the risk of de- 
generative illnesses, reducing the risk of cardiovascular disease, and preventing macular degeneration and cataracts [1]. Carotenoids are naturally occurring tetraterpenes found in various fruits, vegetables, plants, algae and bacteria. Many scholars are interested in microbial pigments due to their natural character, medicinal properties and nutritive value. Wachenroder first separated and crystallized carbohydrates from carrot roots named them as carotenoids [2]. Despite the high production of carotenoids from microorganisms, their use has limitation due to the cell wall resistance, which constitutes a barrier to the bioavailability, requiring the use of techniques for disruption of microbial cells for releasing intracellular products [3]. The choice of an appropriate method for extraction of intracellular bioactive compounds, including pigments are dependent on some aspects such as cell wall strength, intracellular localization, stability and the final use of compound [4]. The extracted carotenoids from microbial would be a cheaper alternative than synthetic carotenoids in aquaculture feed formulations and in surimi based products. A number of research works have been reported over the last few years on carotenoids synthesis by microorganisms, including the bacteria Flavobacterium and Micrococcus, the fungus Blakeslea trispora and yeasts of the genera Phaffia, Rhodotorulaand Sporobolomyces [5] [6]. Yet, little information is available about carotenoids extraction from photosynthetic bacteria. The raw material studied was photosynthetic bacteria, a photoautotrophs characterized by the high levels of carotenoids present in its cellular structure. Zhenxin Gu et al. [7] compared of the three methods ultrasonic assisting, grinding and $\mathrm{HCl}$ assisting on carotenoids extraction yield from $R$. sphaeroides. It was indicated that the $\mathrm{HCl}$-assisted extraction of carotenoids from $R$. sphaeroides is the most effective method [7]. Fengmei Zhao [8] studied the optimal conditions for the production of carotenoids by photosynthetic bacteria ZY2159.

Due to their complex structure and because of the wide variety of these compounds present in vegetables, fruits, algae and bacteria, the choice of an appropriate method for extraction of intracellular bioactive compounds, including pigments is dependent on some aspects such as cell wall strength, intracellular localization, stability and the final use of compound [9]. Mechanical, physical, chemical, enzymatic or a combination of these methods can be applied. There is no generally accepted method or standard method for carotenoids extraction in laboratories. Strong acids and acidic reagents should not be used to extract carotenoids. The extraction of carotenoids must be carried out very quickly, avoiding exposure to light, oxygen, high temperatures and to prooxidant metals, such as iron or copper, in order to minimize autooxidation and cis-trans isomerization [10]. To further develop the photobiological production of carotenoid for commercial purposes, a variety of studies to enhance the carotenoid production via PNSB have been conducted. The most investigated strategy was optimizing the basic parameters, including the operating conditions, substrate selection, immobilization of PNSB cells for a higher retention time, and an integrated system by combining different types of carotenoid-producing microorganisms [4]. 


\section{Materials and Methods}

\subsection{Microorganism and Fermentation Conditions}

A strain of photosynthetic bacterium $R$. faecalis PSB-B (KM272172) was separated from the sludge of the Fenhe River in Shanxi province of China.

The $1000 \mathrm{ml}$ growth medium contained yeast extract $3 \mathrm{~g}$, Peptone $3 \mathrm{~g}, \mathrm{MgSO}_{4}$ $0.5 \mathrm{~g}, \mathrm{CaCl}_{2} 0.3 \mathrm{~g}$. The initial $\mathrm{pH}$ value was adjusted to $6.8-7.2$. Cells were incubated at $30^{\circ} \mathrm{C}$ under $60-\mathrm{W}$ tungsten lamp illumination of 2000lux 3 days.

\subsection{Extraction of Carotenoids}

Three extraction methods for carotenoids from $R$. faecalis were compared. The detailed extraction process of each method was described as follows:

Ultrasonic Extraction: The method of ultrasonic extraction was measured according to the method of $\mathrm{Gu} \mathrm{Z}$ [7] and Hong $\mathrm{ZH}$ [11]. Add acetone solvent into the centrifuge tube. Ratio of solvent to solid, ultrasonic power and duration were set at 40:1 (ml/g), $390 \mathrm{~W}$ and $6 \mathrm{~min}$, respectively. After ultrasonic treatment in ultrasonic crasher for $6 \mathrm{~min}$ in order to break the cells of $R$. faecalis, the flask was kept in water bath of $20^{\circ} \mathrm{C}$. Then make the centrifugal treatment with the mixture in the speed of $3000 \mathrm{r} / \mathrm{min}$ for 10 minutes at $4^{\circ} \mathrm{C}$. The supernatant is the pigment crude extract liquid.

Acid heat crushing Method: Add $5 \mathrm{ml} 3 \mathrm{~mol} / \mathrm{L} \mathrm{HCl}$ into the centrifuge tube; soak it for 1 hour with $20^{\circ} \mathrm{C}$. After that, put it into the 100 degree celsius water to soak for 10 minutes. Then take it out and put it into the ice water to be cooled quickly. Then make the centrifugal treatment with it in the speed of $3000 \mathrm{r} / \mathrm{min}$ for 10 minutes at $4^{\circ} \mathrm{C}$. Abandon the supernatant, we get the cellular mud. Wash the cellular mud with distilled water for 3 to 5 times. Put $20 \mathrm{ml}$ acetone and make the sufficient oscillation. Let it stand for 10 minutes, then make the centrifugal treatment with it in the speed of $3000 \mathrm{r} / \mathrm{min}$ for 10 minutes at $4^{\circ} \mathrm{C}$. The supernatant is the pigment crude extract liquid.

Grinding Method: Put $300 \mathrm{ml}$ bacterial suspension into a centrifuge tube. Then make the centrifugal treatment with it in the speed of $3000 \mathrm{r} / \mathrm{min}$ for 10 minutes at $4^{\circ} \mathrm{C}$. Abandon the supernatant, we get the microbial precipitation. Cells were washed free of medium with distilled water three times. Thallus were freezing-dried through the vacuum freeze dryer. Put some acetone and thallus together with the ratio of liquid to solid is $40: 1$ ( $\mathrm{ml}: \mathrm{g})$, then add some quartz sand into it. Grind it for 30 minutes, then make the centrifugal treatment with it in the speed of $3000 \mathrm{r} / \mathrm{min}$ for 10 minutes at $4^{\circ} \mathrm{C}$. The supernatant is the pigment crude extract liquid.

\section{Determination of Carotenoids}

Total carotenoids content was determined at $480 \mathrm{~nm}$ using a spectrophotometer (722SJinghua, China) following the recommendation of Johnson E A et al. [12].

$$
\text { Caroteniods yield }(\mathrm{mg} / \mathrm{L})=\mathrm{ADV}_{1} / 0.16 \mathrm{~V}_{2}
$$

where $\mathrm{A}$ is the absorbance value of diluted extraction at $480 \mathrm{~nm}, \mathrm{D}$ is the dilu- 
tion rate, $\mathrm{V}_{1}$ is the volume of acetone, 0.16 is the extinction coefficient of carotenoids, and $\mathrm{V}_{2}$ is the volume of fermentation liquor.

\subsection{Experimental Design}

The carotenoids production were statistically evaluated by a one-way analysis of variance (ANOVA), using the SPSS 17.0. In the work described the extraction processes of carotenoids were analysed using three extraction techniques, namely ultrasound-assisted, grinding and $\mathrm{HCl}$-assisted extraction, and the results are compared. Optimization of ultrasonic extraction with Box-Behnken experimental design, the single factor experiment for ultrasound assisted extraction was performed with the analysis of the effect of three factors (extraction time, solvent-solid ratio and extraction power) on extraction of carotenoids from PSB-B. The effects of three factors on carotenoid extraction were obtained. Identified low level and high level (Table 1). Using the Box-Behnken software principle, the three-factor and three-level response surface analysis experiments were carried out with extraction time, extraction power and solid-liquid ratio as independent variables and carotenoids production as the response value (Table 2).

\section{Results and Discussion}

\subsection{Effect of Extraction Method}

In the work described here the extraction processes of carotenoids were analysed using three extraction techniques, namely ultrasound-assisted, grinding and $\mathrm{HCl}$-assisted extraction, and the results are compared. From the results presented in Table 3, it can be concluded that the extraction yields obtained for carotenoids on using ultrasound-assisted extraction are higher than grinding and $\mathrm{HCl}$ assisting extraction .Grinding method and $\mathrm{HCl}$-assisted extraction is lengthy and cannot effectively to break bacteria. Organic solvent which are volatile and harmful to the human body is often adopted in coarse extraction pigment. But ultrasonic method can avoid the organic solvent direct contact with people [13].

\subsection{Optimization of Ultrasonic-Assisted Extraction}

\subsubsection{Effect of Extraction Time on Carotenoids Extraction}

The carotenoids yield increased with the extraction time increasing from $2 \mathrm{~min}$ to $8 \mathrm{~min}$, but decreased when the extraction time were above $6 \mathrm{~min}, 6 \mathrm{~min}$ was

Table 1. Levels of the variables of Box-Behnken design.

\begin{tabular}{cccc}
\hline Factors & Symbols & Low level & High level \\
\hline Extraction time & A & -1 & 1 \\
Extraction power & B & 2 & 6 \\
Solvent-solid ratio & C & 130 & 260 \\
\hline
\end{tabular}


Table 2. Design and results of Box-Behnken design with three independent variables.

\begin{tabular}{|c|c|c|c|c|}
\hline NO. & $\begin{array}{l}\text { A time } \\
(\mathrm{min})\end{array}$ & $\begin{array}{l}\text { B power } \\
(\mathrm{w})\end{array}$ & $\begin{array}{l}\text { C Solvent-solid ratio } \\
\qquad(\mathrm{mg} / \mathrm{ml})\end{array}$ & $\begin{array}{c}\text { Carotenoids Yield } \\
(\mathrm{mg} / \mathrm{L})\end{array}$ \\
\hline 1 & 2 & 195 & 0.5 & 9.22 \\
\hline 2 & 4 & 130 & 1.5 & 11.50 \\
\hline 3 & 2 & 260 & 1 & 9.81 \\
\hline 4 & 4 & 130 & 0.5 & 9.13 \\
\hline 5 & 4 & 195 & 1 & 16.68 \\
\hline 6 & 4 & 195 & 1 & 15.19 \\
\hline 7 & 6 & 195 & 0.5 & 12.49 \\
\hline 8 & 4 & 195 & 1 & 15.95 \\
\hline 9 & 6 & 195 & 1.5 & 10.75 \\
\hline 10 & 2 & 195 & 1.5 & 9.38 \\
\hline 11 & 6 & 260 & 1 & 10.64 \\
\hline 12 & 4 & 260 & 0.5 & 12.74 \\
\hline 13 & 4 & 260 & 1.5 & 11.94 \\
\hline 14 & 6 & 130 & 1 & 14.95 \\
\hline 15 & 2 & 130 & 1 & 11.37 \\
\hline 16 & 4 & 195 & 1 & 16.97 \\
\hline 17 & 4 & 195 & 1 & 15.05 \\
\hline
\end{tabular}

Table 3. Preliminary screening for the method of carotenoids extraction.

\begin{tabular}{cc}
\hline The method of broken cell wall & The yield of carotenoids $(\mathrm{mg} / \mathrm{L})$ \\
\hline HCl assisting & $1.045 \pm 0.052 \mathrm{a}$ \\
Grinding & $1.058 \pm 0.049 \mathrm{a}$ \\
Ultrasound-assisted & $5.292 \pm 0.061 \mathrm{~b}$ \\
\hline
\end{tabular}

Values with different letters $(\mathrm{a}, \mathrm{b})$ differ significantly $(\mathrm{P}<0.05)$.

the optimal temperature at which carotenoids was extracted from Rhodopseudomonas faecalis PSB-B (Table 4). In order to protect the service life of the instrument reason chooses 6 min ultrasonic, rather than choose 8 min or more long time. Pulse interval time can effectively extend the service life of equipment. Cavitation produces high temperature, easy to cause pigment decomposition [14].

\subsubsection{Effect of Extraction Power on Carotenoids Extraction}

Set up six kinds of ultrasonic power: $65 \mathrm{~W}, 130 \mathrm{~W}, 195 \mathrm{~W}, 260 \mathrm{~W}, 325 \mathrm{~W}$ (Table 4). The results showed that the yield of carotenoids increased significantly with increasing extraction power, and then decreased when the extraction power was over $195 \mathrm{~W}$. It was well known that the extraction power facilitated the disruption of cell walls. A larger yield of carotenoids occurred with the stronger extraction power at the early period. However, Ultrasonic cell disruption instrument will have more cavitation at high power. Extreme mechanical strength and heat 
Table 4. Effect of different conditions for extraction on carotenoids yields.

\begin{tabular}{|c|c|c|c|c|c|c|}
\hline \multirow[t]{2}{*}{ Index } & \multicolumn{6}{|c|}{ Extraction time (min) } \\
\hline & $2 \min$ & \multicolumn{2}{|c|}{$4 \mathrm{~min}$} & \multicolumn{2}{|c|}{$6 \mathrm{~min}$} & $8 \mathrm{~min}$ \\
\hline & $5.287 \pm 0.060 \mathrm{a}$ & \multicolumn{2}{|c|}{$5.342 \pm 0.043 a$} & \multicolumn{2}{|c|}{$5.295 \pm 0.061 \mathrm{a}$} & $5.364 \pm 0.053 a$ \\
\hline & \multicolumn{6}{|c|}{ Extraction power $(w)$} \\
\hline Carotenoids & $65 \mathrm{~W}$ & $130 \mathrm{~W}$ & & & $260 \mathrm{~W}$ & $325 \mathrm{~W}$ \\
\hline \multirow[t]{4}{*}{ Yield $(\mathrm{mg} / \mathrm{L})$} & $6.237 \pm 0.232 \mathrm{a}$ & $9.656 \pm 0.138 b$ & 9.806 & $216 b$ & $9.175 \pm 0.103 b$ & $9.064 \pm 0.024 b$ \\
\hline & \multicolumn{6}{|c|}{ Solvent-solid ratio (mg/ml) } \\
\hline & 10:1 & $10: 5$ & & & $10: 15$ & $10: 20$ \\
\hline & $5.868 \pm 0.231 \mathrm{a}$ & $8.55 \pm 0.218 b$ & 11.17 & $.190 c$ & $11.138 \pm 0.193 c$ & $10.027 \pm 0.141 \mathrm{a}$ \\
\hline
\end{tabular}

Values with different letters $(\mathrm{a}, \mathrm{b}, \mathrm{c})$ differ significantly $(\mathrm{P}<0.05)$.

have certain side effects on the production of carotenoids. Under the premise of ensuring the yield of carotenoids, it is more appropriate to choose $195 \mathrm{w}$ for factors such as the life of the instrument [15].

\subsubsection{Effect of Extraction Solvent Systems on Carotenoids Extraction}

The ratio of the optimum fermentation broth to the organic solvent determines the maximum amount of carotenoid extracted from the cells [16]. As the amount of organic solvent increases, the cell concentration decreases, and the viscosity of the liquid increases, which is benefit to cell break. In the study, a suitable ratio can reduce consumption, especially during the commercial extraction of pigments. The effect of solvent-solid ratio on carotenoids extraction is shown in Table 4. The carotenoids yield increased when the ratio was in 0.5 to 2, The result suggested that the solvent-solid ratio of 1 is the optimal ratio for carotenoids extraction.

\subsubsection{Analysis of Box-Behnken Experiment}

W stands for total carotenoids yield, A, B, C denotes the model intercept. A, B, C are the levels of extraction time, extraction power and solvent-solid ratio .By using the Design Expert version 10.0.4 (Stat-Ease, Inc.), a polynomial model describing the correlation between carotenoids yield and the three variables or conditions was obtained as follows (Table 5):

$$
\begin{gathered}
\mathrm{W}=-33.75750+7.21487 \times \mathrm{A}+0.19933 \times \mathrm{B}+30.14450 \times \mathrm{C} \\
-5.28846 \times 10^{-3} \times \mathrm{A} \times \mathrm{B}-0.47500 \times \mathrm{A} \times \mathrm{C}-0.024385 \times \mathrm{B} \\
\times \mathrm{C}-0.64287 \times \mathrm{A}^{2}-4.03314 \times 10^{-4} \times \mathrm{B}^{2}-11.74600 \times \mathrm{C}^{2}
\end{gathered}
$$

with $\mathrm{R}^{2}=0.86$.

The correlative surface response graphs are shown in Figure 1(a). According to the fitted surface graphs, from which we can see that the amount of carotenoids yield increases gradually with the increasing of extration power and extration time. However, the increasing of these two parameters could hardly promote any more carotenoids yield after the response has reached its peak value, extration time can effectively extend the service life of equipment. Cavitation produces high temperature, easy to cause pigment decomposition [17]. 
Table 5. Analysis of variance (ANOVA).

\begin{tabular}{|c|c|c|c|c|c|}
\hline Source & $\begin{array}{l}\text { Sum of } \\
\text { squares }\end{array}$ & $\begin{array}{l}\text { Degree of } \\
\text { freedom }\end{array}$ & $\begin{array}{c}\text { Mean } \\
\text { squares }\end{array}$ & F-value & $\mathrm{P}$-value \\
\hline Model & 100.75 & 9 & 11.19 & 4.75 & 0.0261 \\
\hline A & 10.24 & 1 & 10.24 & 4.34 & 0.0757 \\
\hline B & 0.41 & 1 & 0.41 & 0.18 & 0.4716 \\
\hline C & $1.25 \times 10^{-5}$ & 1 & $1.25 \times 10^{-5}$ & $5.30 \times 10^{-6}$ & 0.6878 \\
\hline $\mathrm{A}^{2}$ & 27.84 & 1 & 27.84 & 11.81 & 0.0109 \\
\hline $\mathrm{B}^{2}$ & 12.23 & 1 & 12.23 & 5.18 & 0.0569 \\
\hline $\mathrm{C}^{2}$ & 36.31 & 1 & 36.31 & 15.40 & 0.0057 \\
\hline $\mathrm{AB}$ & 1.89 & 1 & 1.89 & 0.80 & 0.4003 \\
\hline $\mathrm{AC}$ & 0.90 & 1 & 0.90 & 0.38 & 0.5557 \\
\hline $\mathrm{BC}$ & 2.51 & 1 & 2.51 & 1.07 & 0.3363 \\
\hline Residual & 16.51 & 7 & 2.36 & & \\
\hline Lack of fit & 13.55 & 3 & 4.52 & 6.10 & 0.0565 \\
\hline Pure Error & 2.96 & 4 & 0.74 & & \\
\hline $\mathrm{R}^{2}$ & 0.86 & & & & \\
\hline Adj- $R^{2}$ & 0.68 & & & & \\
\hline Cor Total & 117.26 & 16 & & & \\
\hline
\end{tabular}

Adequate precision $=6.039$.

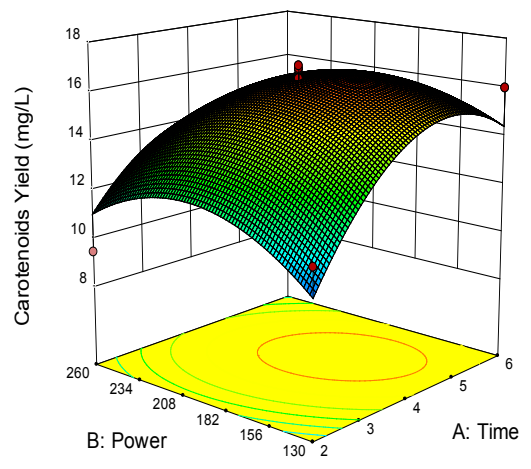

(a)

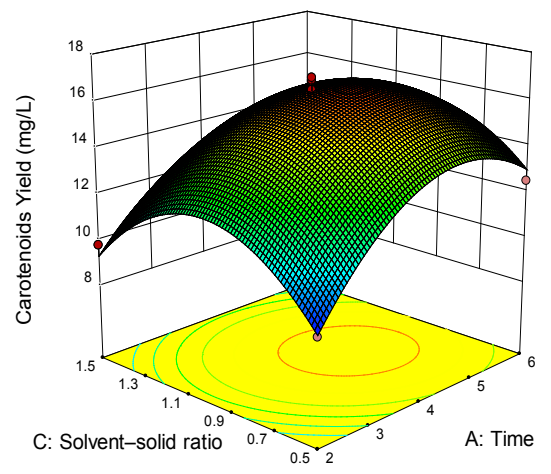

(b)

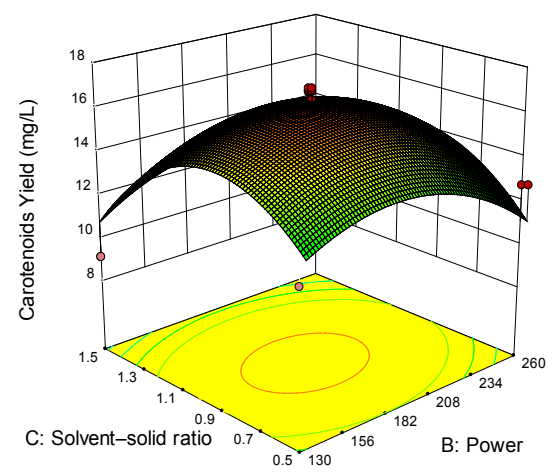

(c)

Figure 1. The effects of ultrasound assisted extraction on carotenoids yields

According to the fitted surface graphs of solvent-solid ratio and extration time (Figure 1(b)), the results show that the effect of solvent-solid ratio and extration time on the carotenoid yield of the strain is parabolic linear, with a maximum value. The contour line is similar to an ellipse indicating that the interaction between the two factors is significant. The yield increases when the solvent-solid ratio increases from 0.5 to 1.0 . It does not continue to increase when the ratio is higher than 1.0.

The effect of solvent-solid ratio and extration power on carotenoids yield is shown in Figure $1(\mathrm{c})$. When the solvent-solid ratio is 1.0, extration power be- 
comes the most factor for improving carotenoids yield. The effect of solvent-solid ratio lead to large difference in carotenoids yield. It could be seen from Figure 1 that the optimal solvent-solid ratio and extration power for carotenoids extraction are 1.0 and $187 \mathrm{w}$. The carotenoids yield could reach to 16.114 $\mathrm{mg} / \mathrm{L}$. If the extration power is less than $187 \mathrm{w}$ the cell wall breaking insufficient. When the extration power is more than $187 \mathrm{w}$, the yield of carotenoids slightly decreases.

\subsection{Effect of Extraction Solvent Systems}

Some organic solvents are not selected as the solvent to extract carotenoids due to their low boiling point. With a slight heat up during sonication the solvent will start vaporizing. Different extract solvents have significant effects on the yield of carotenoids, and the extract effects of single polar organic solvents are diversity. We chose acetone, ethanol, isopropyl alcohol, methanol and acetonitrile as extraction agent. The use of ultrasound facilitates the penetration of the isopropyl alcohol through the faecalis PSB-B cell membrane. The polar solvents help in increasing the permeability of the cell wall of the bacteria and low viscosity increases the diffusion of solvent as well as at low viscosity, acoustic cavitation takes place very easily [18]. Methanol, acetone and isopropanol are relative polar, carotenoids are fat-soluble pigments with less polarity. Therefore, these three organic solvents were selected to mixed with the n-hexane, petroleum ether, and ethyl acetate. Finally, methanol and N-hexane were selected as extractants. We investigated the effect of mixed ratio of solvent to extract the carotenoids. The ratio of the extractant was determined to be N-hexane:Methanol= $(5: 1)$.

\subsection{Repetitive Experiment}

Multiple sets of repetitive experiments were performed under optimal extract conditions. The test has good reproducibility, and the average extraction amount of carotenoids is $15.86 \mathrm{mg} / \mathrm{L}$.

\section{Conclusion}

Extraction of carotenoids from Rhodopseudomonas faecalis PSB-B is investigated in this work. Three methods of extracting carotenoids were compared by experiments. The results showed that the ultrasonic assisted extraction method can obtain more carotenoids than others. Maximum amount of carotenoids recovered was $16.11 \mathrm{mg} / \mathrm{L}$ obtained by ultrasonic assisting using at ultrasonic time 4.5 min, solvent-solid ratio (10:10), extraction power of $187 \mathrm{~W}, \mathrm{~N}$-hexane:Methanol = (5:1).

\section{Acknowledgements}

This work was financially supported by the Natural Science Foundation Project of Shanxi Province (201801D121206) and the Natural Science Foundation of 
Modern College of Humanities and Sciences of Shanxi Normal University (2018JCYJC01). The authors would like to thank Zhang Hong for her help in statistical analysis of data.

\section{Conflicts of Interest}

The authors declare no conflicts of interest regarding the publication of this paper.

\section{References}

[1] Santos, D.T. and Meireles, M.A.A. (2010) Carotenoid Pigments Encapsulation: Fundamentals, Techniques and Recent Trends. Open Chemical Engineering Journal, 2010, 4.

[2] Mezzomo, N., Paz, E., Maraschin, M., et al. (2012) Supercritical Anti-Solvent Precipitation of Carotenoid Fraction from Pink Shrimp Residue: Effect of Operational Conditions on Encapsulation Efficiency. The Journal of Supercritical Fluids, 66, 342-349. https://doi.org/10.1016/j.supflu.2011.08.006

[3] Michelon, M., de Borba, T.M., da Silva Rafael, R., et al. (2012) Extraction of Carotenoids from Phaffia rhodozyma: A Comparison between Different Techniques of Cell Disruption. Food Science and Biotechnology, 21, 1-8.

https://doi.org/10.1007/s10068-012-0001-9

[4] Farkade, V.D., Harrison, S. and Pandit, A.B. (2005) Heat Induced Translocation of Proteins and Enzymes within the Cell: An Effective Way to Optimize the Microbial Cell Disruption Process. Biochemical Engineering Journal, 23, 247-257.

https://doi.org/10.1016/j.bej.2005.01.001

[5] Lampila, L.E., Wallen, S.E., Bullerman, L.B., et al. (1985) The Effect of Illumination on Growth and $\beta$-Carotene Content of Blakeslea trispora Grown in Whey. Lebensmittel-Wissenschaft Technologie, 18, 370-373.

[6] Sakaki, H., Nakanishi, T., Tada, A., et al. (2001) Activation of Torularhodin Production by Rhodotorula glutinis Using Weak White Light Irradiation. Journal of Bioscience and Bioengineering, 92, 294-297. https://doi.org/10.1016/S1389-1723(01)80265-6

[7] Gu, Z.X., Chen, D.M., Han, Y.B., et al. (2008) Optimization of Carotenoids Extraction from Rhodobacter sphaeroides. LWT-Food Science and Technology, 41, 1082-1088. https://doi.org/10.1016/j.lwt.2007.07.005

[8] Zhao, F.M. and Zhao, C.G. (2007) Study on Fermentation of Carotenoids by Photosynthetic Becteria ZY2159. Food Science, 28, 209-212. (In Chinese)

[9] Quackenbush, F.W. and Smallidge, R.L. (1986) Nonaqueous Reversedphase Liquid Chromatographic System for Separation and Quantitation of Provitamins A. Journal of the Association of Official Analytical Chemists, 69, 767-772.

[10] Sun, M. and Temelli, F. (2006) Supercritical Carbon Dioxide Extraction of Carotenoids from Carrot Using Canola Oil as a Continuous Co-Solvent. The Journal of Supercritical Fluids, 37, 397-408. https://doi.org/10.1016/j.supflu.2006.01.008

[11] Zhang, H. and Hu, Q.P. (2015) Isolation, Identification and Physiological Characteristics of High Carotenoids Yield Rhodopseudomonas fecalis PSB-B. International Journal of Recent Scientific Research, 6, 3893-3899.

[12] Johnson, E.A. and Lewis, M.J. (1979) Astaxanthin Formation by the Yeast Phaffia rhodozyma. Journal of General Microbiology, 115, 173-183.

ttps://doi.org/10.1099/00221287-115-1-173 
[13] Khachik, F., Beecher, G.R. and Whittaker, N.F. (1986) Separation, Identification and Quantification of the Major Carotenoid and Chlorophyll Constituents in Extracts of Several Green Vegetables by Liquid Chromatography. Journal of Agricultural and Food Chemistry, 34, 603-616. https://doi.org/10.1021/jf00070a006

[14] Pico, Y. (2012) Chemical Analysis of Food. In: Pico, Y., Ed., Techniques and Applications, Elsevier, Oxford, UK, 117.

[15] Charest, D.J., Bulaban, M.O., Marshall, M.R. and Cornell, J.A. (2001) Astaxanthin Extraction from Crawfish Shells by Supercritical $\mathrm{CO}_{2}$ with Ethanol as Co-Solvent. Journal of Aquatic Food Product Technology, 10, 79-93.

[16] Soumen, D. and Rathod, V.K. (2013) Ultrasound Assisted Extraction of $\beta$-Carotene from Spirulina platensis. Ultrasonics Sonochemistry, 20, 271-276.

https://doi.org/10.1016/j.ultsonch.2012.05.010

[17] Kwon, J.H., Belanger, J.M.R., Pare, J.R., et al. (2003) Application of the Microwave-Assisted Process $\left(\mathrm{MAP}^{\mathrm{Tm}}\right)$ to the Fast Extraction of Ginseng Saponins. Food Research International, 36, 491-498.

https://doi.org/10.1016/S0963-9969(02)00197-7

[18] Tinoi, J., Rakariyatham, N. and Deming, R.L. (2005) Simplex Optimization of Carotenoid Production by Rhodotorula glutinis Using Hydrolyzed Mung Bean Waste Flour as Substrate. Process Biochemistry, 40, 2551-2557.

https://doi.org/10.1016/j.procbio.2004.11.005 